Part of Journal of Research of the National Bureau of Standards, Volume 27, August 1942

\title{
MICROSCOPIC STRUCTURE OF THE WOOL FIBER
}

\author{
By Charles W. Hock, Robert C. Ramsay, and Milton Harris ${ }^{1}$
}

\begin{abstract}
An investigation was undertaken to obtain information concerning the fine details of structure of wool fibers and especially of their constituent scale and cortical cells. Treatment of chemically modified wool with the enzyme, pepsin, was found to be an excellent method for releasing individual cells for such studies,

It is shown by microdissection that the striated appearance of the cortical cells is due to the presence of many fibrils which can be separated with microneedles. Near the center of each cell is a nucleus which has a granular structure. Between crossed nicols, the fibrillar part of the cortical cells appears birefringent, whereas the nucleus does not.

The scales show little internal organization such as exhibited by the cortical cells. When examined with crossed nicols they appear nonbirefringent. Unlike the cells of the cortex, the scales are not easily separated by treatment with enzymes, but remain attached to each other in a manner comparable to the arrangement of shingles on a roof.

A comparison of root and shaft of the fiber reveals numerous differences in reaction to microchemical color tests, as well as differences in cellular structure. The root, for example, gives a positive test for sulfhydryl groups whereas the shaft gives a negative test. Similarly, the shaft appears birefringent whereas the root does not. These and other observations clearly indicate that as the cells of the root emerge into the shaft a number of physical and chemical changes take place simultaneously.

When wool is placed in chlorine water, swellings arise on the surface of the fibers (Allwörden reaction). Evidence is presented in support of the view that these sacs arise solely from the scales and that their formation is associated with the reaction of the chlorine with disulfide groups of the cystine in the scales.
\end{abstract}

\section{CONTENTS}

I. Introduction . 181

II. Materials $\ldots$

III. Experimental procedure and results

1. Separation of cortical and scale cells

2. Structure of the cortical cells

3 . Structure of the scale cells

4. Differences between root and shaft

5. Allwörden reaction. 187

IV. References $\ldots$

\section{INTRODUCTION}

Wool fibers are specialized appendages of the epidermis of the sheep, and show many similarities to other skin tissues, such as nails, horns, and feathers. A growing fiber consists of a root and shaft, the former being the living region situated beneath the surface of the skin, whereas the latter is the nonliving portion that extends above the skin surface.

1 Research Associates at the National Bureau of Standards, representing the Textile Foundation. 
Increase in length of the fiber is brought about by the proliferation of new cells in the root and the subsequent emergence of these cells into the shaft. The shaft is composed of dead cellular units which usually are arranged in three layers-an outer layer of scales, a middle region called the cortex, and a central core or medulla. The relative thickness of each of these layers varies considerably in different fibers. Kemp, for example, has a large medulla, whereas in the best grades of wool the medulla is either absent or very small.

Much of this knowledge of the structure of the fiber was contributed by the early researches of Nathusius [1] ${ }^{2}$ and McMurtrie [2]. These investigators obtained considerable information concerning the shape, length, and fineness of wool, and in addition described the various types of cells which comprise the fiber. A number of the structural details were also noted later by Kronacher and Lodeman [3], von Bergen [4], Reumuth [5], and Müller [6], as well as others. In the present investigation these earlier observations have been extended in order to obtain additional information on the fine details of structure of the fibers and especially of their constituent cells.

\section{MATERIALS}

Two samples of wool were used in the investigation. One consisted of domestic wool, for the most part nonmedullated, which was purified by successive extractions with ethyl alcohol and with ether for 16 hours each, followed by washing with water at $40^{\circ} \mathrm{C}$. A second sample was obtained from the Bureau of Animal Industry, United States Department of Agriculture. ${ }^{3}$ It consisted of wool carefully pulled from the back of a Hampshire sheep so as to have the roots attached to the shaft, and also of small pieces of skin, which were cut directly from the sheep and placed in fixing fluids.

\section{EXPERIMENTAL PROCEDURE AND RESULTS}

\section{SEPARATION OF CORTICAL AND SCALE CELLS}

When wool fibers are mounted in water and examined with a microscope, much can be learned about the size, shape, and appearance of the surface of the fibers, but very little is learned of the detailed structure of their constituent cells. In order to study the minute structure of the various types of cells, the fibers must be treated in a way that makes a more detailed microscopic examination possible. For this purpose thin cross and longitudinal sections can be employed to good advantage, but the liberation of single cells from the fibers is even more satisfactory.

The liberation of cells from fibers by various chemical reagents, enzymes, and bacteria has been frequently reported in the literature. The treatments with chemical reagents usually involve the use of strong acids or alkalies and are sufficiently drastic to produce more or less profound changes in structure. Treatment of the fibers with enzymes is in many respects more satisfactory and has been used considerably in the present investigation.

Although untreated wool is highly resistant to the action of enzymes, it has been shown in work now in progress in this laboratory [7] that

2 Figures in brackets indicate the literature references at the end of this paper.

3 Acknowledgment is made to J. I. Hardy for supplying this material. 
fibers in which disulfide cross-linkages have been ruptured by reduction with thioglycolic acid and then methylated to prevent re-formation of the linkages are rapidly attacked by treatment with an enzyme such as pepsin. Accordingly, it was decided to follow, microscopically, the changes which reduced and methylated wool undergoes in pepsin, in an effort to obtain information concerning the structure and behavior of the cells. For comparison, untreated fibers were similarly examined. ${ }^{4}$ Samples of each were placed in vials containing a solution of the enzyme. At the same time, single fibers were placed in a drop of enzyme on a microscope slide and protected with a cover glass, which was sealed to the slide with vaseline. The latter method made possible the continuous observation of a single fiber over a relatively long period. The specimens were examined and fresh enzyme was added every 2 or 3 days. The experiments were run at two temperatures - one at room temperature $\left(22^{\circ}\right.$ to $\left.25^{\circ} \mathrm{C}\right)$ and another at $35^{\circ} \mathrm{C}$. The material kept at the higher temperature was the first to show evidence of attack by the enzyme, but otherwise the two series ultimately presented essentially the same microscopic appearance.

In agreement with the other work [7], it was found that untreated wool was not readily attacked by pepsin. Even after long exposure to the enzyme these fibers showed little evidence of damage except for frayed ends, and sometimes the liberation of a few cortical cells. The reduced and methylated wool was attacked more rapidly. Cells obtained from this wool had the same initial appearance as cells obtained in a similar manner from untreated wool. However, as will be shown later, cells from untreated wool were resistant to further action of the enzyme whereas cells from reduced and methylated samples were eventually digested. With reduced and methylated wool, even at room temperature, changes in the fiber were detectable in less than 24 hours. The free ends of the fiber were usually frayed, and some intermediate parts appeared to be darkened and crushed. After several days pronounced changes had taken place. The fibers had lost their lustre and exhibited a pronounced striated appearance due to the increased prominence of the cortical cells. After continued treatment with enzymes, large numbers of cortical cells were liberated from the fibers (fig. $1, A, B$, and $C$ ). The cortical cells were removed not only from the ends of the fiber but from intermediate parts as well, leaving in extreme cases practically intact tubes of scale cells (fig. 1,C). In regions where only part of the cortex was removed from a given area, it was found that the first cells to be liberated lay next to the scales. Additional cortical cells were released upon applying pressure to the cover glass.

The enzyme apparently had easier access to the cut ends of the fiber and thus brought about greater deterioration in those regions. This behavior has also been noted by other investigators. Photomicrographs by von Bergen [4] indicate that after certain chemical treatments the ends show the most damage. From the work of Royer and Millson [8] on dyed wool it is evident, also, that the ends of the fibers take up dye more rapidly than do intermediate parts. Similar results, indicative of the greater liability to attack at the ends, were

${ }^{4}$ A solution of pepsin was prepared by dissolving $1 \mathrm{mg}$ of the crystalline enzyme in $1 \mathrm{ml}$ phosphate buffer at $\mathrm{pH}$ 1.2. A few drops of merthiolate were added to the solution as a preservative.

$200723-41-6$ 
obtained in the present investigation. Furthermore, when the ends of untreated and of reduced and methylated fibers were sealed with glue before placing the fibers in pepsin, it was found that the breakdown of the fibers was retarded. After a few weeks in the enzyme, however, this difference between fibers with sealed and with unsealed ends was lost, both samples then showing similar degrees of disintegration.

In order to study further the action of pepsin on untreated and on reduced and methylated wool, cross sections, cut 10 to 15 microns thick with the Hardy device [9], were placed either in vials containing the enzyme or in drops of the latter on microscope slides. Even after a month there were only slight changes in the untreated sections (fig. $2, A)$. With sections of reduced and methylated wool the cortex was eaten out, leaving in extreme cases only a thin ring of scales (fig. 2, C). The degree of breakdown of the wool was related to the length of exposure to the enzyme (compare fig. 2, $B$, with fig. 2, $C$ ). Furthermore, the rate of digestion appeared to be associated with the extent of reduction of the wool, as reduced and methylated fibers with 90 percent of the disulfide cross-linkages broken were much more rapidly attacked by the enzyme than those in which only 50 percent of the linkages had been disrupted. When free cortical cells, released from partially reduced and methlyated fibers upon treatment with pepsin, were placed in fresh enzyme for a period of 1 month, some of the cells appeared to be digested whereas others from the same sample remained practically intact. These differences appear to be associated with the extent of reduction of the wool and suggest that the undigested cells may be ones in which most of the cross-links are intact.

The results of these experiments indicate that the scale cells are resistant to the action of pepsin and that the ease with which single cortical cells are liberated depends on the previous chemical treatments which the fibers received. Although cortical cells may be rapidly separated from each other by the action of pepsin, individual cells show further signs of disintegration only after continued treatment with the enzyme.

\section{STRUCTURE OF THE CORTICAL CELLS}

Single cortical cells are spindle-shaped. They vary in size depending on the sample of wool. Walther [10] found that their average size varied from 80 to 110 microns in length, 2 to 5 microns in width, and 1.2 to 1.6 microns in thickness. Cortical cells liberated from fibers by the action of chemical agents frequently show evidence of fimbriated ends. In most cases, also, the cells are prominently striated.

On careful examination of single cells liberated from the cortex by the action of pepsin, a structure located near the center of the cell and resembling a nucleus was frequently observed (fig. $3, A$ ). This central region did not, however, stain with common nuclear dyes such as hematoxylin and methylene blue. Figure $3(A)$ shows also that the nucleus is granular, whereas the rest of the cell is fibrillar in appearance.

Nuclei are not easily observed in untreated cross sections, but are clearly visible after the latter have been properly stained or swollen [5]. 
For example, treatment of the sections with pepsin, sodium carbonate, or with a combination of both these reagents rendered the outline of individual cortical cells and their nuclei distinct (fig. 4). Furthermore, when the cells were treated with Orange II $^{5}$ (a dye which readily stains wool) the cells became deep orange, but this central region was only lightly stained. Upon examination with crossed nicols, a dark, central, elongated area was nearly always detectable in the bright cell (fig. $3, \vec{B}$ ). In other words, each birefringent cortical cell possesses a nonbirefringent nucleus. Finally after continued treatment with pepsin, many of the cortical cells were nearly eaten in two at the middle (fig. $3, C$ ), even though the cell is widest at this point. This suggested that the nucleus consists of a material which is more readily attacked by the enzyme than is the rest of the cell.

The structural details of the cortical cells were further investigated by dissecting them with the aid of a micromanipulator. Upon careful manipulation it was possible to insert two fine glass needles into a single cell and pull it apart. When this was done, it was found that the cell was composed of many fibrils (fig. $5, A, B$, and $C$ ). When examined between crossed nicols, the latter appeared to be birefringent. Small and large groups of fibrils were dissected from the cell, and in some cases all the fibrils were spread out in the form of a fan. By this technique it was possible to prove that the striated appearance of the cortical cells is due to the presence of fibrils and not merely to surface irregularities or diffraction phenomena.

\section{STRUCTURE OF THE SCALE CELLS}

As already described, the scales, unlike the cells of the cortex, were not appreciably affected by pepsin. They usually remained attached to each other in the form of tubes (fig. 1, $A, B$, and $C$ ) corresponding to their arrangement in intact fibers, or at least in rather large groups, which furnished excellent material for a microscopic examination. The liberation of single scale cells was relatively infrequent, nor were additional ones readily released upon applying pressure to the cover glass. Although the scales stained poorly, the addition of a dye such as Orange II was helpful in showing their arrangement. It was clear after staining that the scales overlapped in a manner comparable to the arrangement of shingles on a roof (fig. 6). Except for a few indistinct markings on the surface, individual scales showed little evidence of internal structure.

When handled with microneedles, groups of scales freed by the action of pepsin appeared to be rather pliable, although the individual scale cells were not easily separated from each other. They could, nevertheless, be torn apart in such a way as to form chunks of scale material. In so doing there was no obvious fibrillar structure such as that shown by the cortical cells.

When the Feulgen test for nucleic acid (see section III-4) was applied to untreated wool fibers, the scale cells of the shaft gave a negative test. Scales liberated from the fibers by various treatments were also examined in an effort to detect nuclei. Although structures superficially resembling nuclear bodies were observed occasionally in these cells, their presence could not be demonstrated clearly nor consistently.

A 1.4-percent solution of Orange II at $\mathrm{pH} 1.5$ was used. 
Scales released by treatment with acids, alkalies, enzymes, or by mechanical scraping were examined between crossed nicols. In all cases, the scales, both before and after staining, showed practically no birefringence.

Additional information concerning the structure of the scales is contained in the section on the Allwörden reaction.

\section{DIFFERENCES BETWEEN ROOT AND SHAFT}

Since the cells of the root are alive and growing, whereas the cells of the shaft are dead, it is not surprising to find profound physical and chemical differences between these two regions of the fiber. Several of these differences were revealed when microchemical color tests were applied to wool fibers a short time after they had been carefully pulled from the back of a sheep so as to have the roots attached to the shaft.

These fibers were stained according to Feulgen's technique [11, 12], which is considered to be specific for nucleic acid. A positive test is indicated by the red coloration obtained when a fuchsin-sulfurous acid solution is applied to the nucleus. Fibers which had been given this test showed a root which was stained deep red, whereas the shaft remained colorless (fig. 7). This difference could be detected even with the unaided eye. Upon mounting the stained fibers in a medium of higher refractive index and examining with a microscope, individual nuclei were observed (fig. 8). At the base of the root the nuclei and cells were relatively large and more or less rounded. Farther from the base the nuclei and cells were elongated. In some cases the nuclei were very narrow and slit-like, although distinctly red. A little below the level where the fiber emerges from the skin there was a rather abrupt change in the reaction of the nuclei, that is, they gave a negative Feulgen test in the shaft. That this difference did not appear to be caused by poor penetration of the dye into the shaft was indicated by the fact that fibers from which the scales had been removed by mechanical treatment still failed to give a positive test.

In order to study further the changes which take place as the cells pass from the root to the shaft, longitudinal sections were made of pieces of sheepskin with fibers attached. The tissue was embedded in a mixture of paraffin and cellulose acetate [13], cut into sections according to the usual cytological procedure, and then stained either with hematoxylin or according to the method of Feulgen. The cells of the root had a somewhat roundish shape and a more or less granular appearance. The cells of the shaft, on the other hand, were elongated and distinctly fibrous. These facts are undoubtedly related to observations made with crossed nicols, which show that the shaft of the fiber is birefringent whereas the birefringence of the root is negligible. In agreement with the results obtained with single fibers, the nuclei in the cells of the root were found to give a positive reaction to Feulgen's test. Nuclei were observed in those cells of the root which gave rise to scales as well as in those which gave rise to cortical cells.

When a single fiber was mounted in dilute ammonium hydroxide and treated with sodium nitroprusside, a pink to red color was developed in the root, whereas the shaft of the fiber remained colorless (fig. 9). The red coloration obtained with sodium nitroprusside 
indicates that at least some of the sulfur in the root is present in sulfhydryl form. This is in agreement with the findings of previous investigators $[14,15,16,17,18]$, who showed that the sulfhydrylcontaining substance is limited to the living cellular parts of the epidermis and its appendages. In order to be sure that the difference in reaction between the root and shaft was not caused merely by a differential rate of penetration of the reagent, the scales were mechanically removed from a few fibers. The results with such fibers were in agreement with those obtained in the original test.

The biuret test for proteins, the Sakaguchi test for arginine, and the Millon and Pauly tests for tyrosine were also applied to single fibers. These tests did not reveal any differences between the root and shaft, except that the former gave a positive test more quickly.

The differences between the root and shaft may be summarized as follows:

\begin{tabular}{|c|c|}
\hline Root & Shaft \\
\hline $\begin{array}{l}\text { Soft and easily crushed. } \\
\text { Cells roundish. } \\
\text { Positive test for nucleic acid. } \\
\text { Nuclei stained with hematoxylin. } \\
\text { Cytoplasm granular in appearance. } \\
\text { Not birefringent. } \\
\text { Positive test for sulfhydryl groups. } \\
\text { No Allwörden reaction with chlorine } \\
\text { water. }\end{array}$ & $\begin{array}{l}\text { Tough and horny. } \\
\text { Cells elongated. } \\
\text { Negative test for nucleic acid. } \\
\text { Nuclei unstained with hematoxylin. } \\
\text { Cells distinctly fibrous. } \\
\text { Birefringent. } \\
\text { Negative test for sulfhydryl groups. } \\
\text { Many large Allwörden "sacs". }\end{array}$ \\
\hline
\end{tabular}

\section{ALLWÖRDEN REACTION}

When wool fibers are placed in chlorine water, the so-called Allwörden reaction takes place $[19,20]$. This treatment causes the formation of sacs $^{6}$ on the surface of the fiber (fig. 10, $A$ and $B$ ). That the formation of these sacs is in some way associated with the scales has been suggested by many investigators [5, 19, 20, 21, 22, 23]. It is not clear, however, from a review of the literature, whether the sacs arise solely from the scales or whether the latter are merely pushed out by the swelling of a layer of material which lies beneath them. Since this is pertinent to an understanding of the structure of the fibers, the reaction was investigated in detail.

Although sacs form quickly with saturated chlorine water, their formation is slowed down by the use of dilute solutions. Likewise, the reaction is retarded, or even completely inhibited, by certain types of damage to the fiber. The first evidence of sacs is the appearance on each scale of a small swelling which gradually increases in size until the sac involves the entire scale surface. Incipient swelling did not appear to be confined to a particular part of the scale, such as base or tip. In a few cases two or more foci of swelling occurred in a single scale and were observed to flow together to form one large sac. It was also evident from the experiments that the size and shape of the sacs was associated with similar properties of the scales.

The sacs usually appeared optically empty. After certain treatments, however, particles showing Brownian movement were observed in them. As described by Kronacher and Lodemann [3], these particles were especially numerous when fibers which had been stained

"Since the swellings are shown to be protein membranes flled with liquid, "sac" is believed to be a more appropriate descriptive term than "bubble," which is in widespread use in the literature. 
with picric acid were placed in aqueous methylene blue subsequent to their treatment with chlorine water. In agreement with the observations of Kronacher and Saxinger [22], it was found that the thin membrane of a sac could be stroked with a needle of the micromanipulator without causing the sac to burst, but just as soon as the microneedle pierced the membrane the sac collapsed, leaving small bits of the membrane still attached to the fiber. Likewise, the sacs collapsed after prolonged treatment with chlorine water, and after exposure to certain chemical agents, especially alkalies (fig. 11). The sacs were stained by dyes, such as methylene blue and malachite green, and this treatment was helpful in studying their size and shape.

When cross sections about as thick as the length of the scales of wool fibers were treated with chlorine water, typical sacs were formed. The latter appeared to arise superficially on the surface of the scales. There was no swelling of the region just inside the scales, such as might have been expected if some part of the fiber in addition to the scales was directly involved in the formation of sacs. Although the results of this experiment, as well as some observations with intact single fibers, suggest that the scales alone give rise to sacs, this fact could not be demonstrated clearly by these techniques.

In untreated wool the scales are closely appressed to one another (fig. 12, A). In carrying out some preliminary experiments during the course of this investigation, however, it was noted that certain chemical treatments loosened the scales and caused them to bend away from the fiber. For example, when wool fibers were placed in concentrated sulfuric acid for an hour or less, or in concentrated formic acid for several weeks, the scales were loosened in a way which resembled warped shingles on a roof (fig. 12, $B$ ). After prolonged treatment with these acids, single scales, or small groups of scales, were completely separated from the fibers. Scales which had been loosened or liberated in this way were excellent for studying the origin of the sacs. After removal from the acid, the fibers were washed with distilled water and then placed in chlorine water. Sacs formed quickly, and in agreement with the conclusions of Müller [6], it was evident that they came from the scales alone. It was clear, also, that the sacs were formed between the upper and lower surfaces of each individual scale cell. A small swelling first appeared somewhere in the scale, and then increased in size until the whole scale was swollen to resemble a little ellipsoidal bag (fig. 12, $C$ ). Both the upper and lower surfaces of a sac appeared to be of approximately equal thickness. After their formation, the sacs on loose scales showed the same behavior to dyes and chemical reagents as the sacs on fibers which had not been treated with acids. In cases where the scales were loosened from each other but not bent away from the fiber, the formation of sacs aided in the further separation of the scales. Sometimes sacs were formed on completely isolated scales; at other times where only fragments of single scales were treated with chlorine, sacs were not formed although the two layers of the scale were seen to separate. Apparently in the latter instance true sacs could not form because of the torn edges of the scales. The relationship between the formation of sacs in untreated and in acid-treated fibers is shown diagrammatically in figure 13.

Chlorine water caused the formation of sacs on all parts of a wool fiber except the root (fig. 14). Tests on hairs from more than a score 

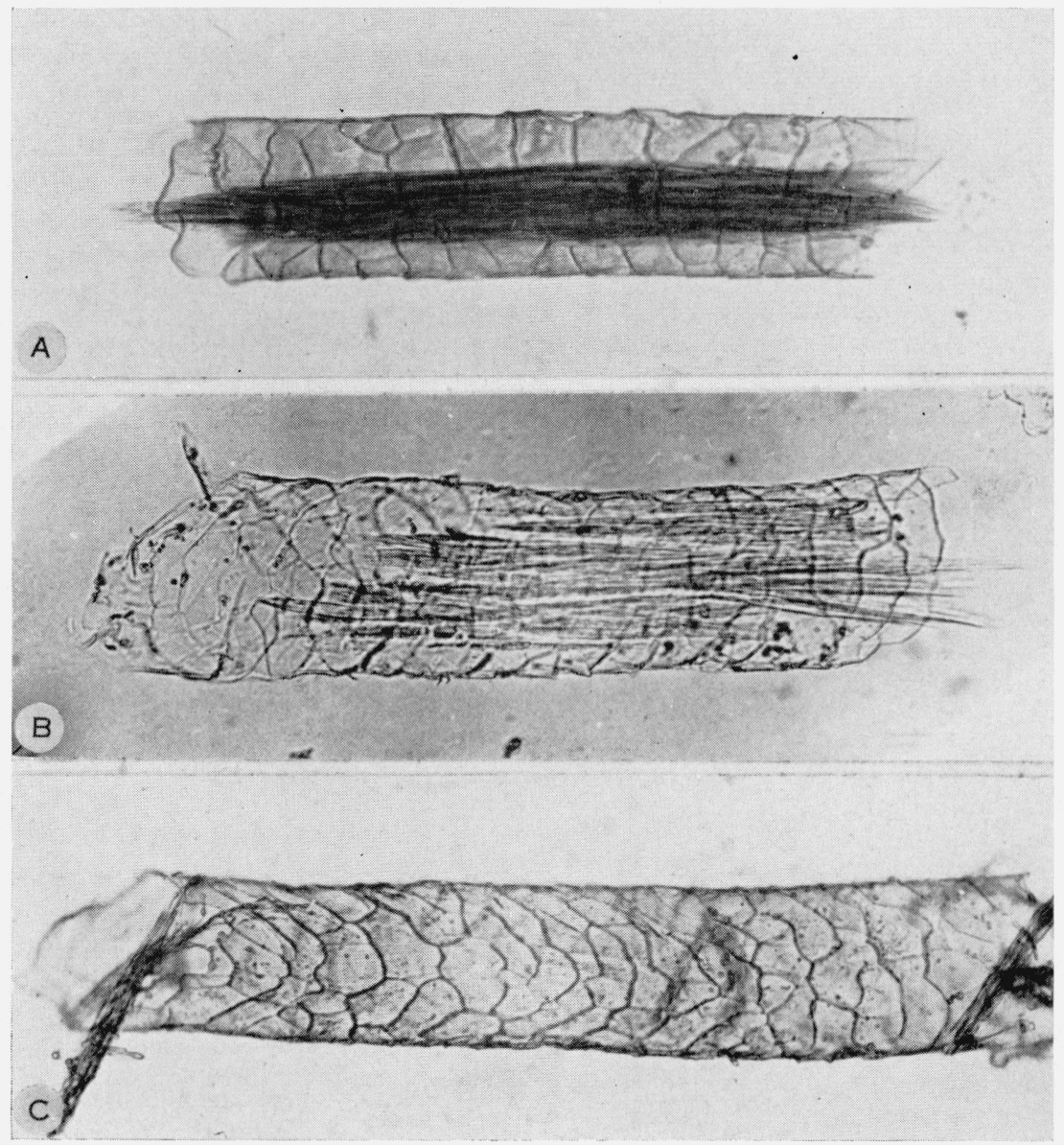

FIGURE 1.-Reduced and methylated wool fibers treated with solutions of pepsin. $A, B$, and $C$ show three stages in the removal of cortical cells from the fibers. $A$ and $B$ unstained: $C$ stained with Orange II. Magnification $\times 350$. 


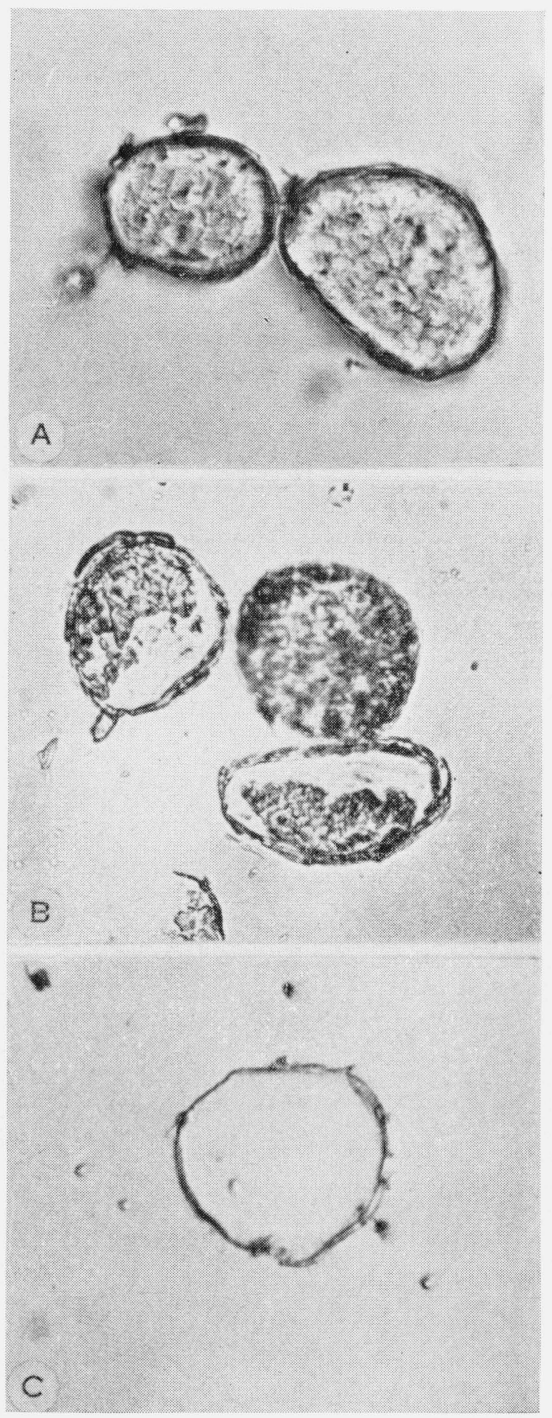

FIGURE 2.-Cross sections of wool fibers treated with solutions of pepsin.

$A$, Sections of untreated fibers in pepsin for 1 month. $B$, Sections of reduced and methylated fibers in pepsin for 10 days. $C$, Section of reduced and methylated fiber in pepsin for 1 month, showing only the thin ring of scales which remains. Magnification $\times 450$. 

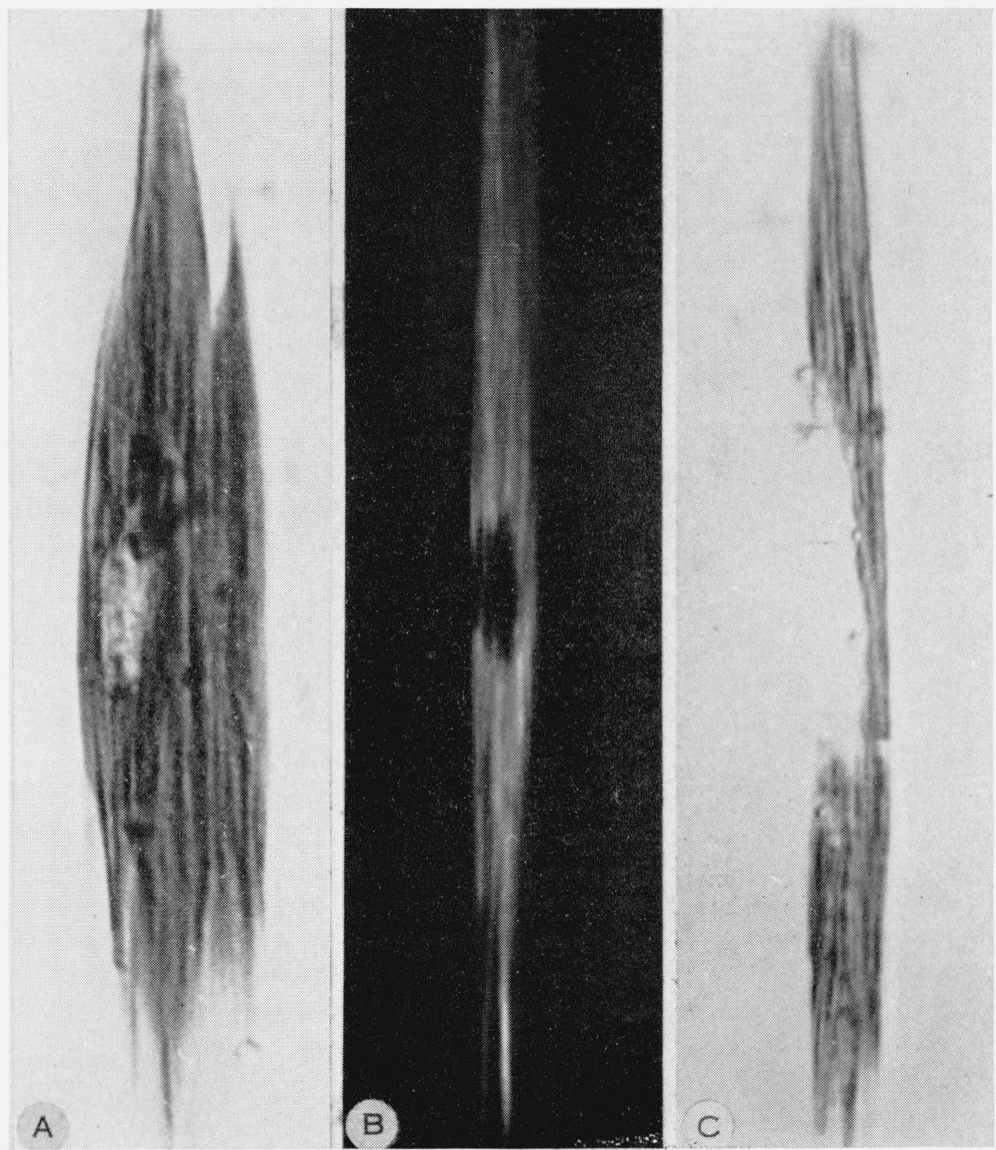

FIGURE 3.- Single cortical cells from reduced and methylated fibers photographed under various conditions.

$A$, Cell, stained with Orange II, showing the nucleus and the fibrillar appearance of the rest of the cell. $B$, Cell, between crossed nicols, showing the nonbirefringent nucleus in the birefringent cell. $C$, Single cell nearly eaten in two by the prolonged action of pepsin. Magnification $\times 1,400$. 


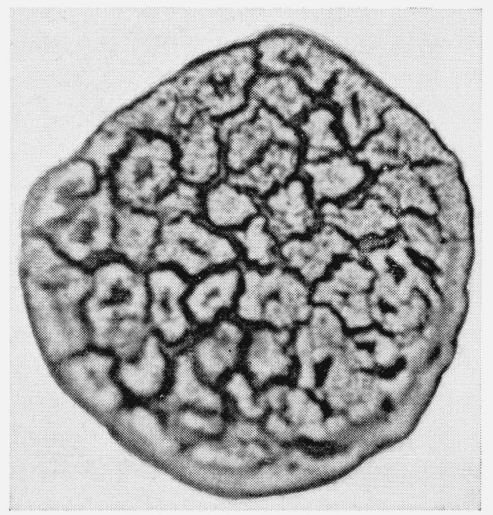

FIGURE 4.-Cross section of an untreated wool fiber after several weeks in a solution of pepsin followed by swelling with 9-percent sodium carbonate.

The photomicrograph shows the outline of the individual cortical cells and their nuclei. Magnification $\times 1,500$. 

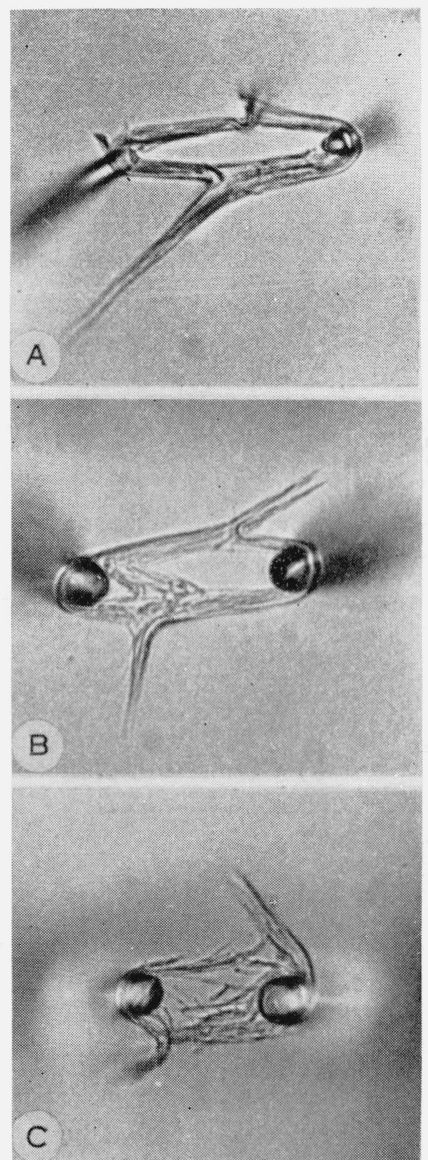

FIGURE 5.-Cortical cells being dissected with microneedles to show their fibrillar structure.

Magnification $\times 500$. 


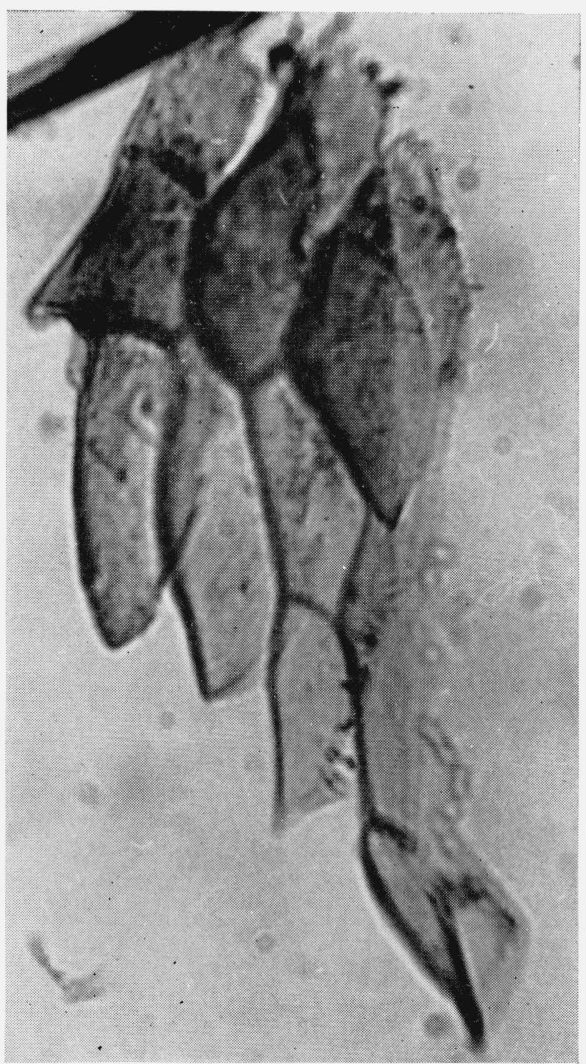

FIGURE 6.-Group of scales released by the action of pepsin on reduced and methylated fibers.

Stained with Orange II. Magnification $\times 1,120$. 


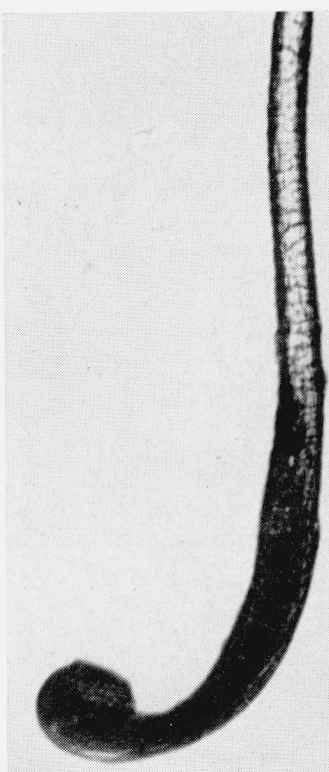

FigURE 7.--Single fiber (recently pulled from the back of a sheep) stained according to Feulgen's technique, showing the dark-colored root indicative of a positive test for nucleic acid.

Fiber mounted in water. Magnification $\times 120$. 


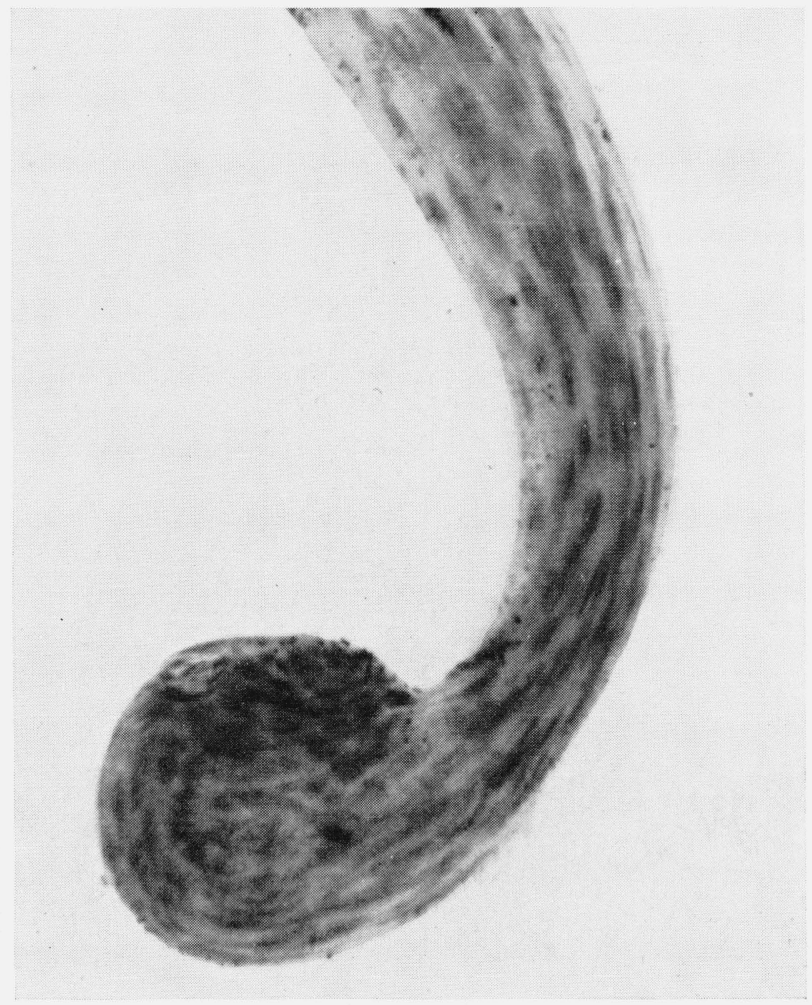

Figure 8.-Root of a wool fiber showing individual nuclei in the cells of the root. Fiber stained according to the technique of Feulgen and mounted in tricresyl phosphate. Magnification $\times 500$. 


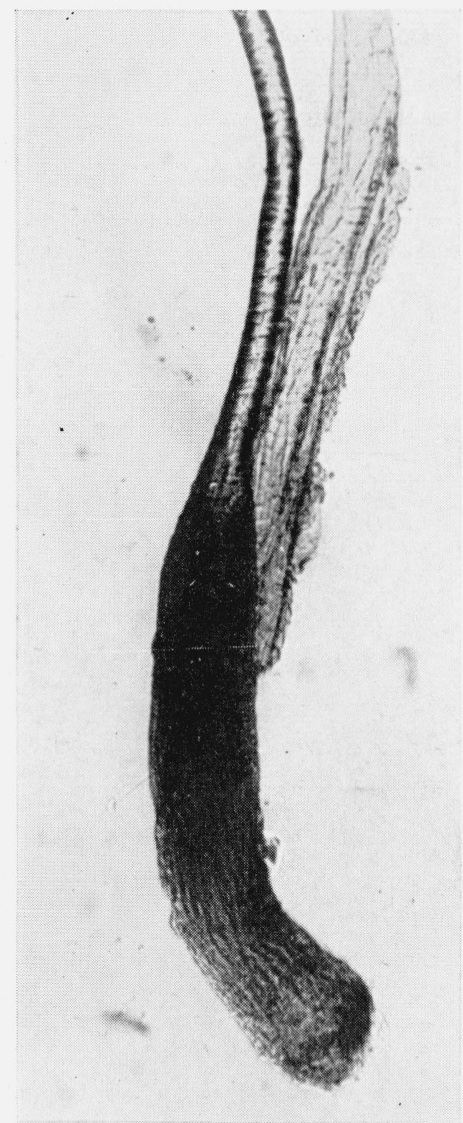

FIGURE 9.- Single fiber (pulled from the back of a sheep) treated with sodium nitroprusside.

The dark color of the root indicates the presence of sulfhydryl groups. Part of the cuticle of the follicle remains attached to the fiber. Magnification $\times 120$ 


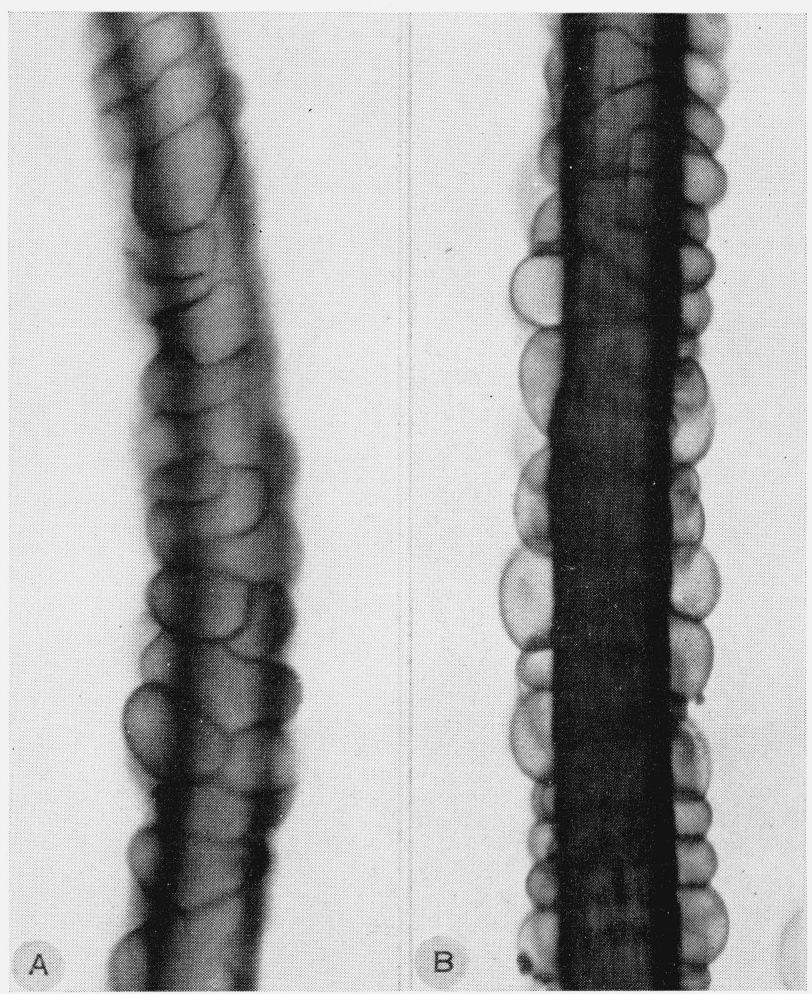

FIGURE 10.-Fibers treated with saturated chlorine water to give the Alluörden reaction.

$A$, Surface view of a fiber after sac formation. $B$, Fiber in focus approximately midway between its upper and lower surfaces. Fibers stained with aqueous methylene blue. Magnification $\times 500$. 


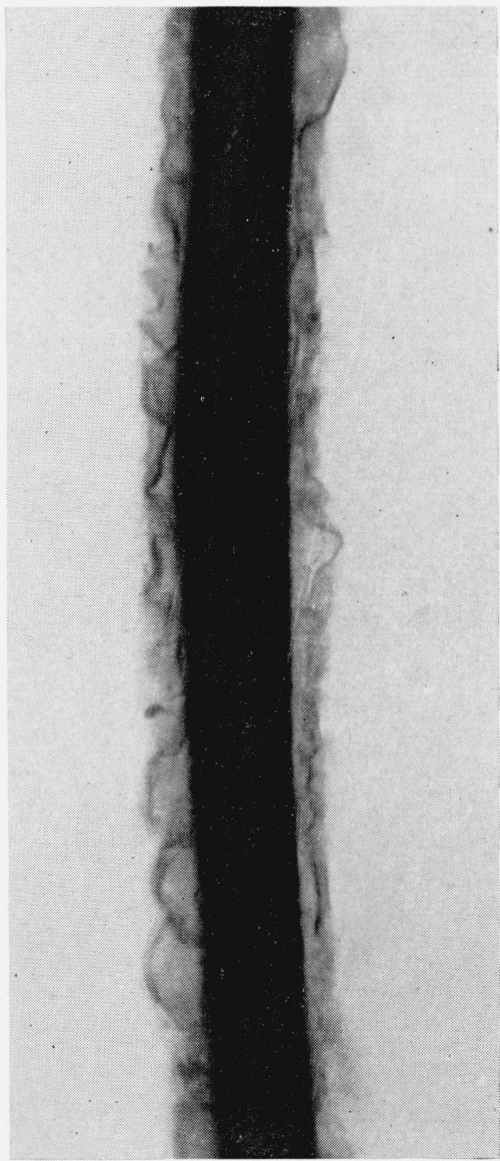

Figure 11.-Effect of alkali on Allwörden sacs.

Single fiber treated with chlorine water, methylene blue, and then 1-percent sodium hydroxide, showing the collapsed sac membranes at the surface of the fiber. Magnification $\times 500$. 

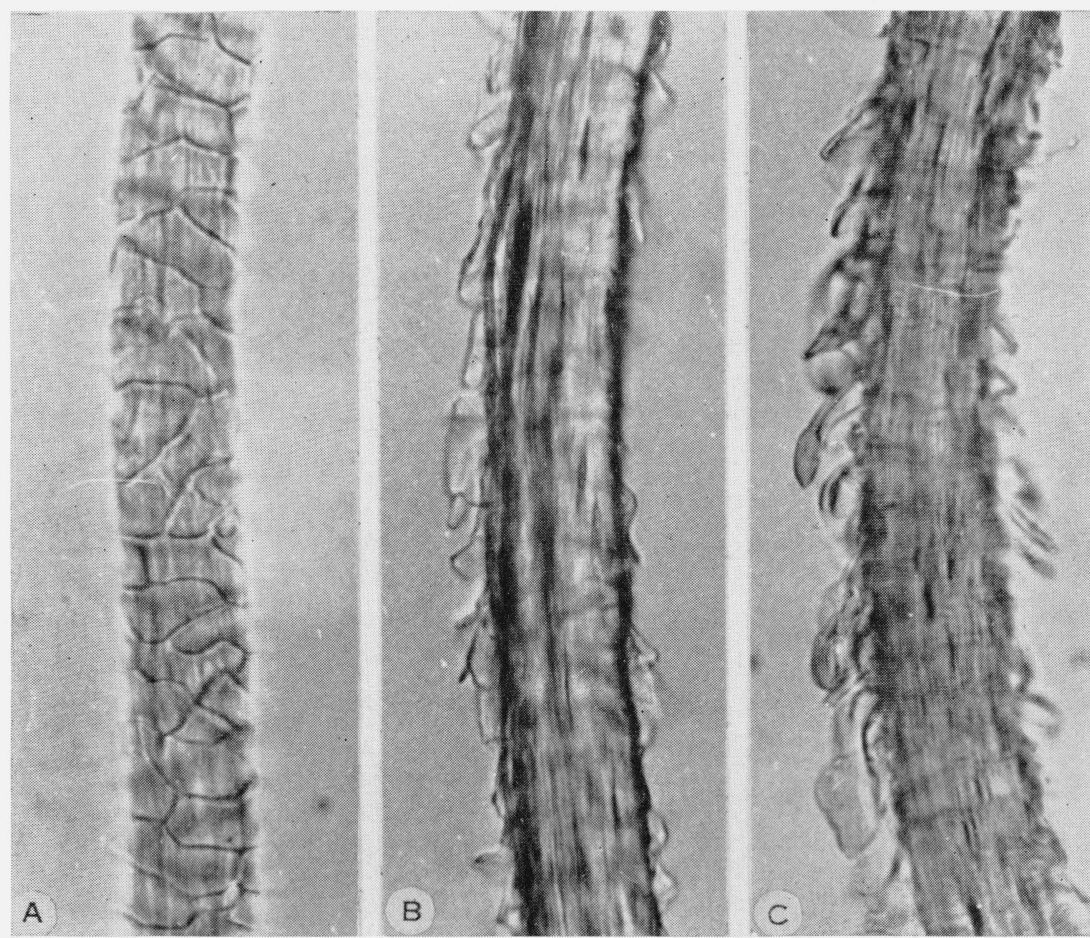

Figure 12.-Scales and their relation to the formation of Allwörden sacs.

$A$, Fiber mounted in water and photographed in surface view to show the arrangement of the scales. $B$, Fiber treated with concentrated sulfuric acid to loosen scales, $C$, Fiber treated with sulfuric acid to loosen the scales, and then with chlorine water to form sacs. The photomicrograph shows several sacs in various stages of formation, each arising from an individual scale. Magnification $\times 425$. 
Journal of Research of the National Bureau of Standards

Research Paper 1412

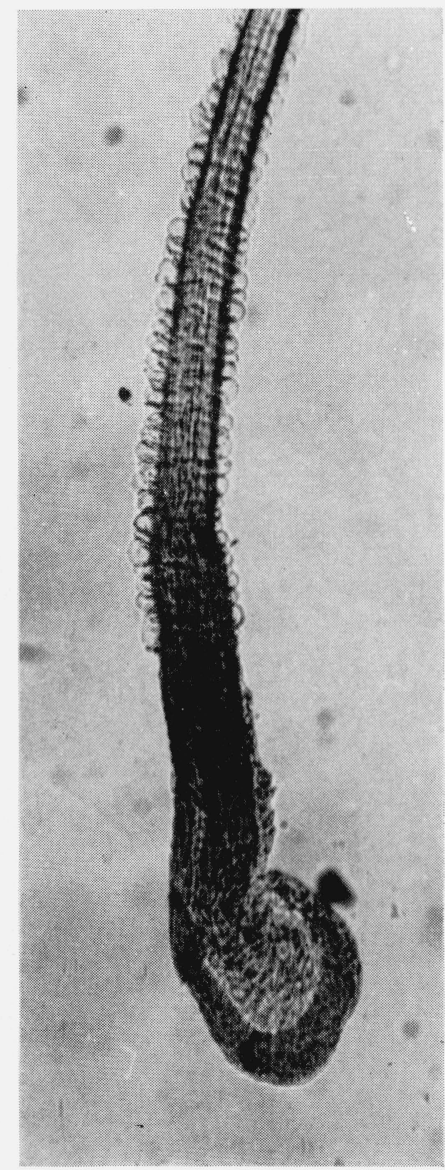

FIGURE 14.-Fiber showing root and part of the shaft, after treatment with chlorine water.

Many sacs arise in the shaft but none in the root. Magnification $\times 120$. 


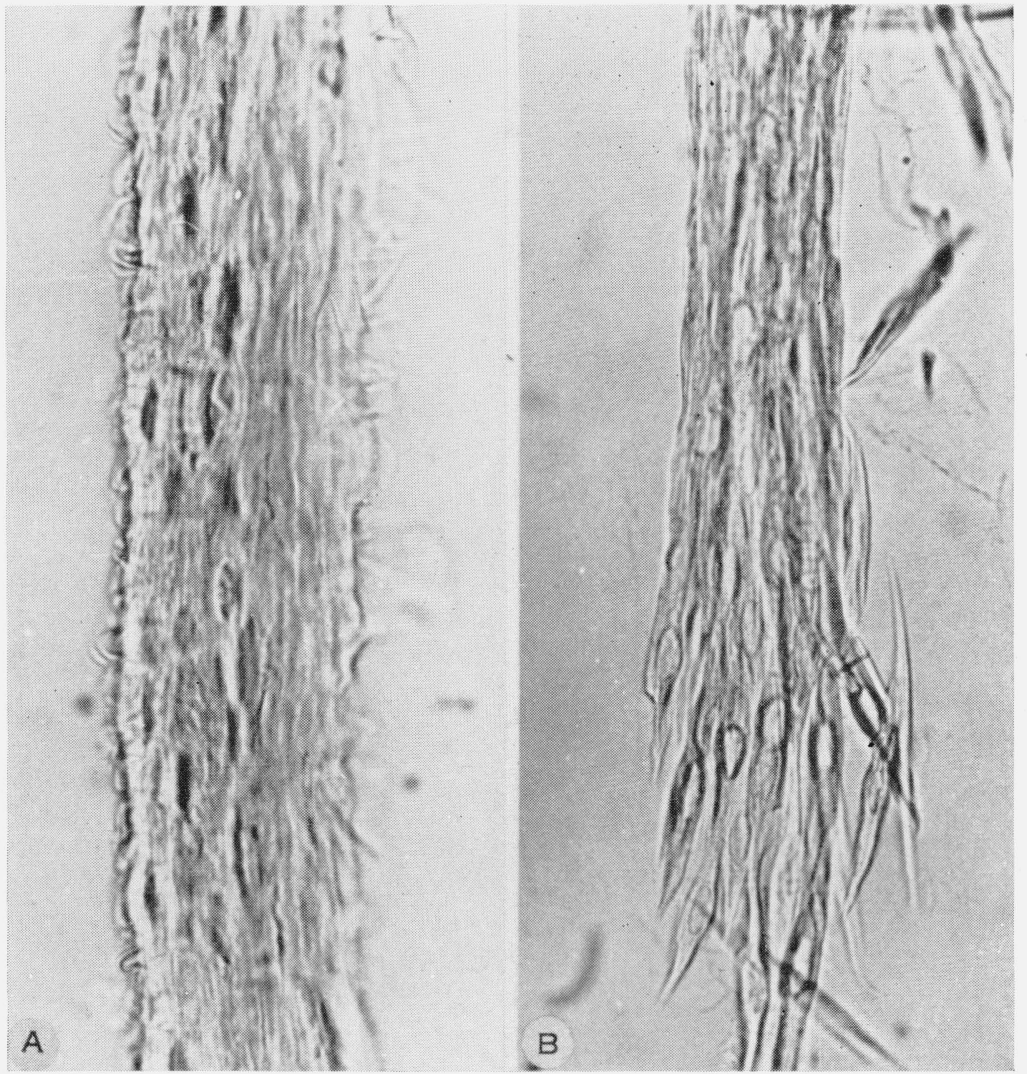

FIGURE 15.-Fibers showing swellings in the cortex after treatment with acid and chlorine water.

$A$, Wool fiber after 2 hours in concentrated sulfuric acid followed by treatment with chlorine water. $B$, Wool fiber after 14 months in concentrated formic acid followed by treatment with chlorine water. Similar results were obtained with fibers that had been boiled in the acid for about 4 hours. Magnification $\times 450$. 


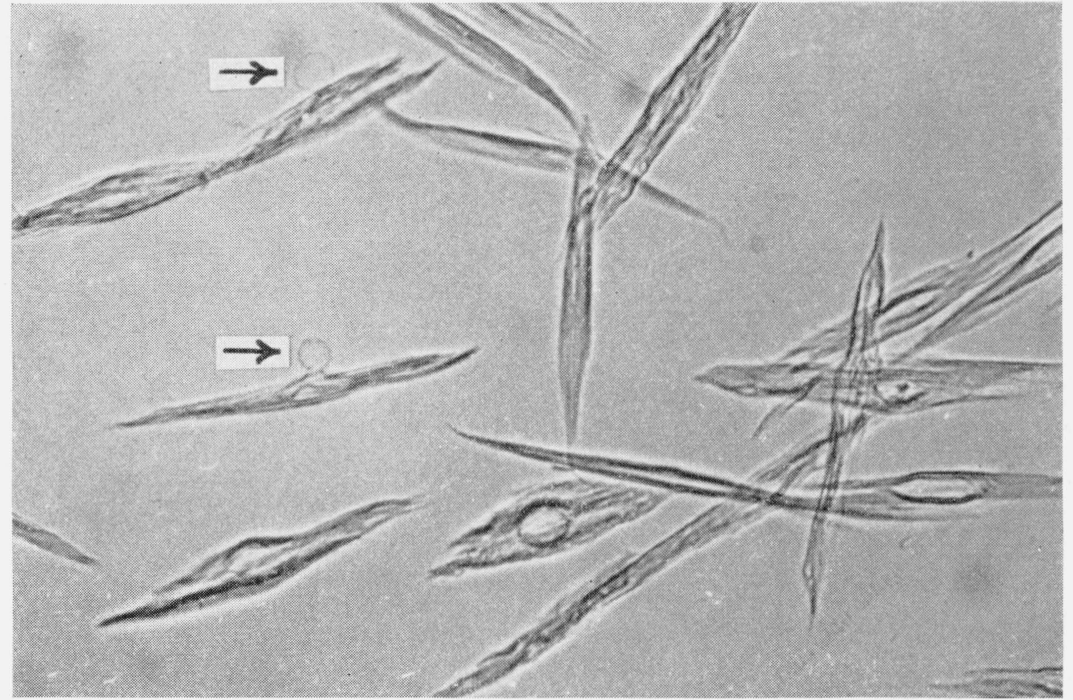

Figure 16.-Individual cortical cells showing swollen nuclei after treatment with chlorine water.

The cells were released by the prolonged action of concentrated formic acid, and then, after washing in distilled water, treated with chlorine. Arrows indicate additional swellings which sometimes arise from the nucleus. Magnification $\times 420$. 
of common and rare animals were, likewise, found to give the Allwörden reaction.

In order to study further the conditions necessary for the formation of Allwörden sacs on the scales, untreated wool was placed in a 0.6percent solution of sodium carbonate at $50^{\circ} \mathrm{C}$. At various intervals thereafter, samples of the wool were removed, washed in acid and in water, and finally placed in chlorine water. The number, size, and rapidity of formation of the sacs was observed microscopically. It was found that sac formation was retarded with increasing length of alkali treatment. Mark [24] has similarly shown that the number of

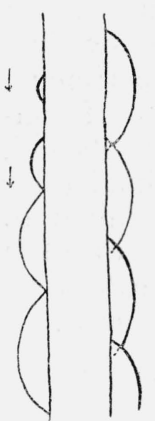

A

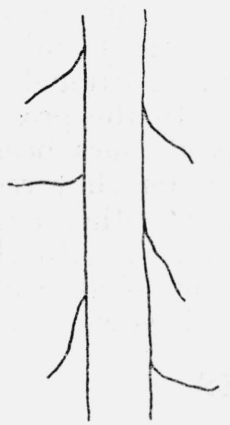

B

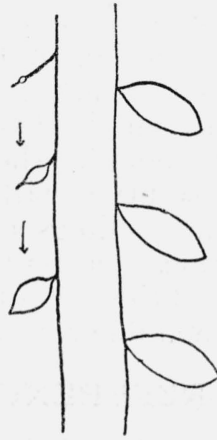

c sacs formed on a fiber by chlorine water was decreased as the concentration of the carbonate and the temperature at which the reaction was carried out were increased. In the present investigation, chemical analysis of the fibers showed that as the cystine content of the fibers decreased, because of the action of the carbonate, sac formation was retarded. Similarly, samples of wool which were degraded by photochemical reactions showed poor sac formation. The extent of the sac formation varied with the duration of the irradiation. Samples of wool degraded
in this way also had appreciably reduced cystine contents $[25,26]$. The Allwörden reaction was also tried on samples of wool in which the mode of linkage of the sulfur had been altered by treatments such as reduction and alkylation. In all cases the sacs were formed more quickly when the cystine content was high, whereas the formation of sacs did not occur when the cystine content was lowered sufficiently. While not all of the above chemical treatments are specific for cystine in wool, it is significant, nevertheless, that samples of wool with low cystine contents fail to give the Allwörden reaction. The results suggest that the formation of sacs is dependent on the specific reaction of chlorine with unaltered disulfide groups of the cystine in the scales of the fiber. That chlorine can react with cystine has already been demonstrated [27]. A possible mechanism is that the disulfide linkages are split and oxidized to strongly acid groups such as perhaps sulfonic acid groups. An osmotic type of swelling could then take place to form the sacs noted. Further evidence favoring this view is obtained when concentrated salt solutions are added to the fibers after the reaction with the chlorine. Under these conditions the sacs contract.

It was noted, during the course of the above experiments with acidtreated wool, that when the scales gave rise to typical sacs, localized swellings often appeared in the cortex (fig. 15, $A$ and $B$ ). In order to study this phenomenon further, wool fibers were treated with acid for 
longer periods in order not only to loosen the scales but to release individual cortical cells as well. Fibers which had been placed in concentrated sulfuric acid at room temperature for 1 to 2 hours, or in boiling concentrated formic acid for about 6 hours, were found to be suitable for these experiments. Individual cortical cells released by these treatments showed distinct signs of swelling when placed in chlorine water. It was obvious, moreover, that the swelling in each cell was confined principally to the nucleus (fig. 15, B, and fig. 16). In some cases additional swellings appeared to arise as buds from the swollen nucleus (fig. 16). Swollen nuclei were not observed in fibers which had been treated with alkali or other reagents which prevent the Allwörden reaction. Although the foregoing observations suggest that the typical Allwörden reaction of the scales and the swelling cortical nuclei may be related phenomena, additional experiments pointed to dissimilarities between the two. In the presence of concentrated salt solutions, for example, the scale sacs became flaccid, and upon replacing the salt solution with water they regained their former turgidity; the nuclear swellings on the other hand failed to react in this way. Furthermore, a gentle prick with the tip of a microneedle was sufficient to bring about the collapse of scale sacs, whereas this did not occur when nuclear swellings were punctured.

\section{REFERENCES}

[1] W. V. Nathusius, Das Wollhaar des Schafes (Berlin, 1866).

[2] W. McMurtrie, Wool and Other Animal Fibers (Government Printing Office, Washington, 1886).

[3] C. Kronacher and G. Lodemann, Technik der Haar und Wolleuntersuchung (Berlin, 1930).

[4] W. von Bergen, American Wool Handbook (American Wool Handbook Publishing Co., New York, N. Y., 1938).

[5] H. Reumuth, Klepzig's Textil-Z. 21, 352 and 34, 495 (1939).

[6] C. Müller, Zellforsch. Mikroskop. Anat. [A] 29, 1 (1939).

[7] W. B. Geiger, W. I. Patterson, L. R. Mizell, and M. Harris. (Publication in preparation).

[8] G. L. Royer and H. E. Millson, Am. Dyestuff Reptr. 29, 697 (1940).

[9] J. I. Hardy, U. S. Dept. of Agriculture Circular 378 (1935).

[10] A. R. Walther, Landw. Jahrb. 55, 531 (1920-21).

[11] R. Feulgen and H. Rosenbeck, Z. physik. Chem. 135, 203 (1924).

[12] C. E. McClung, Handbook of Microscopical Technique (Hoeber, New York and London, 1939.

[13] C. M. Barlow, J. Text. Inst. 29, T111 (1938).

[14] E. Buffa, J. physiol. path. génér. 6, 645 (1904).

[15] E. Walker, J. Physiol. 59, 32 (1924).

[16] E. Walker, Biochem. J. 19, 1085 (1925).

[17] G. H. Perceval and C. P. Stewart, Brit. J. Dermatology and Syphilis 42, 215 (1930).

[18] P. Wels, Archiv exptl. Path. Pharmakol., 188, 265 (1938).

[19] v. Allwörden, Studien über Einwirkung von Chlor auf Schafwolle. Diss. Berlin (1913).

[20] v. Allwörden Z. angew. Chem. 29, 77 (1916).

[21] P. Krais and P. Waenting, Z. angew. Chem. 33 (1920).

[22] C. Kronacher and G. Saxinger, Z. Tierzücht. Züchtungsbiol. Tierernähr. 4, $30(1925)$ and $5,3(1926)$.

[23] W. Spöttel, Melliands Textilber. 6, 605 (1925).

[24] H. Mark, Einzeldarst a. d. Kaiser-Wilhelms Institut f. Faserstoffchem. 1 (1925).

[25] H. A. Rutherford and M. Harris, J. Research NBS 23, 597 (1939) RP1255.

[26] M. Harris and A. L. Smith, J. Research NBS 19, 563 (1938) RP 1091.

[27] M. Harris and A. L. Smith, J. Research NBS 17, 577 (1936) RP928.

Washington, May 8, 1941. 